\title{
Impact of apo E genotype on postprandial TAG-rich lipoprotein in healthy men
}

\author{
V. Calabuig-Navarro ${ }^{1}$, C. M. Walden ${ }^{2}$, J. A. Lovegrove ${ }^{1}$, A. M. Minhane ${ }^{1,3}$ and K. G. Jackson ${ }^{1}$ \\ ${ }^{1}$ Department of Food and Nutritional Sciences, University of Reading, RG6 6AP, UK, ${ }^{2}$ Unilever Discover, Colworth Science \\ Park, Sharnbrook, MK44 ILQ, UK and ${ }^{3}$ Department of Nutrition, Norwich Medical School, University of East Anglia, \\ NR4 7TJ, UK
}

The concentration of plasma fasting and postprandial TAG and TAG-rich lipoproteins (TRLs) composition and particle size, are recognised as being important determinants of atherogenesis and CVD risk ${ }^{(1)}$. apoE is a protein found associated with TRLs and apoE genotype in part determines responsiveness to dietary fat change with the greatest reduction in LDL cholesterol levels evident in apoE4 carriers following the switch to a low fat/low cholesterol diet. However, the responsiveness to acute changes in dietary fat composition is less clear.

Our aim was to examine the impact of the apoE genotype on the response of postprandial plasma TAGs, the composition of TRL with Svedberg flotation rates $\left(S_{\mathrm{f}}\right)>400, S_{\mathrm{f}} 60-400$ and $S_{\mathrm{f}} 20-60$ and lipoprotein particle size, to meals of varying fatty acid composition. Twenty-one healthy men (mean (SD), age 48 (16) years and BMI $26(3) \mathrm{kg} / \mathrm{m}^{2}$ ), were recruited according to apoE genotype (10 apoE3/3, 11 apoE3/E4). They consumed in random order a mixed meal containing $50 \mathrm{~g}$ of fat rich in either SFA, unsaturated fatty acids (UNSAT) or SFA with fish oils (FO, $5.75 \mathrm{~g}$ DHA and $0.83 \mathrm{~g}$ EPA) on three separate occasions. Fasting and frequent postprandial blood samples were collected until $480 \mathrm{~min}$ after the meal.

\begin{tabular}{|c|c|c|c|c|c|c|c|c|}
\hline & & & \multicolumn{6}{|c|}{ TRL-TAG } \\
\hline & \multicolumn{2}{|c|}{ Plasma TAG } & \multicolumn{2}{|c|}{$S_{\mathrm{f}}>400$} & \multicolumn{2}{|c|}{$S_{\mathrm{f}} 60-400$} & \multicolumn{2}{|c|}{ Sf $20-60$} \\
\hline & \multicolumn{2}{|c|}{$\mathrm{AUC}^{\dagger}$} & \multicolumn{2}{|c|}{$\mathrm{AUC} \dagger$} & \multicolumn{2}{|c|}{$\mathrm{AUC}^{\dagger}$} & \multicolumn{2}{|c|}{$\mathrm{AUC} \dagger$} \\
\hline & Mean & $\mathrm{SE}$ & Mean & $\mathrm{SE}$ & $\overline{\text { Mean }}$ & $\overline{\mathrm{SE}}$ & Mean & $\overline{\mathrm{SE}}$ \\
\hline \multicolumn{9}{|c|}{$\overline{\mathrm{E} 3 / \mathrm{E} 3(n \text { 10) }}$} \\
\hline SFA & 929.7 & 144.5 & 45.8 & 11.7 & 117.8 & 14.5 & 52.1 & 9.1 \\
\hline FO & 823.9 & 101.4 & 55.8 & 24.6 & 134.5 & 22.3 & 58.4 & 8.3 \\
\hline UNSAT & 1002.5 & 169.7 & 50.1 & 13.8 & 138.1 & 36.8 & 42.4 & 7.5 \\
\hline \multicolumn{9}{|c|}{$\mathrm{E} 3 / \mathrm{E} 4(n$ 11) } \\
\hline SFA & 996.1 & 105.3 & 36.8 & 5.8 & 110.3 & 16.7 & 48.1 & 8.4 \\
\hline FO & 897.8 & 111.6 & 43.9 & 11.9 & 174.9 & 44.6 & 59.3 & 7.2 \\
\hline UNSAT & 986.5 & 106.9 & 65.9 & 21.6 & 223.7 & 55.4 & 64.1 & 10.7 \\
\hline
\end{tabular}

$\dagger$ Units for AUC are $\mathrm{mmol} / \mathrm{l} \times 480 \mathrm{~min}$.

There was no significant impact of apoE genotype on AUC for the total postprandial TAG responses or any of the TRL fractions after the three meals. A significant genotype $(P=0.015)$, time $\times$ genotype $(P=0.008)$ and meal $\times$ time $\times$ genotype $(P=0.003)$ effect was observed in the particle size of the $S_{\mathrm{f}}>400$ fraction. A significant genotype effect in the time to reach peak TAG concentration in the $S_{\mathrm{f}}$ 20-60 fraction $(P=0.032)$, with later peak times in the apoE3/E4 group following any meal compared with apoE3/E3 (unpublished results).

Overall, our data indicate that the $a p o E$ genotype has little impact on the postprandial TAG response following test meals of varying fat composition.

1. Nordestgaard BG, Benn M, Schnohr P et al. (2007) Jama-Journal of the American Medical Association. 298, $299-308$. 